\title{
Expression and mutational status of USP8 in tumors causing ectopic ACTH secretion syndrome
}

\section{Dear Editor,}

One of the most common paraneoplastic syndromes is the ectopic ACTH secretion syndrome (EAS), a sustained hypercortisolism driven by tumors of extra-pituitary origin that secrete either adrenocorticotropic hormone (ACTH), its precursor proopiomelanocortin (POMC, unprocessed or partially cleaved) or, less frequently, corticotropin-releasing hormone (CRH). Bronchial carcinoids and small cell carcinomas of the lung (SCLC) are the most frequent causes of EAS (Alexandraki \& Grossman 2010). This syndrome is commonly associated with an increased risk of morbidity and mortality since patients with hypercortisolism usually exhibit worse response to chemotherapy and suffer from severe infections and metabolic complications during treatment (Terzolo et al. 2001).

The mechanisms underlying the ectopic production of ACTH are still not well understood. Recently, we and others have reported that the gene coding for the human ubiquitin-specific protease 8 (USP8) is recurrently mutated in $50 \%$ of all the investigated ACTH-producing corticotroph adenomas causing sporadic Cushing's disease (Ma et al. 2015, Perez-Rivas et al. 2015, Reincke et al. 2015). Mutant USP8 triggers POMC transcription and ACTH secretion through the stabilization of the epidermal growth factor receptor (EGFR) (Reincke et al. 2015). As USP8 mutations are considered causative for Cushing's disease, we investigated whether USP8 is involved in the ectopic production of ACTH by endocrine tumors.

Therefore, we performed a retrospective, single-center analysis using formalin-fixed, paraffin-embedded samples of 15 patients ( 7 females and 8 males) who developed EAS and were treated and followed up in our hospital since 1986. Patients were included when presenting with persistent ACTH-dependent hypercortisolism (Cushing's syndrome) of confirmed non-pituitary origin. Cushing's syndrome was diagnosed based on the clinical signs and symptoms of hypercortisolism (easy bruising, facial plethora, proximal muscle weakness, purple striae, low-impact bone fractures, mood changes, irregular menstruation, infertility or impotence, hypokalemic hypertension, myopathy and hyperglycemia) together with increased levels of latenight salivary cortisol ( $>145 \mathrm{ng} / \mathrm{dL}$ ), urinary free cortisol $(>150 \mu \mathrm{g} / 24 \mathrm{~h})$ and/or lack of suppression of cortisol $(>1.8 \mu \mathrm{g} / \mathrm{dL})$ after administration of dexamethasone, following the recommendations of the Endocrine Society (Nieman et al. 2008). Non-pituitary ACTH dependency was confirmed by levels of basal plasma ACTH $>15 \mathrm{pg} / \mathrm{mL}$, less than $50 \%$ suppression of serum cortisol during an $8 \mathrm{mg}$ high-dose dexamethasone test, lack of response of ACTH and cortisol to CRH and/or a negative inferior petrosal sinus sampling. The tumor was considered to be the cause of ECS when tumor tissue stained positive for ACTH immunoreactivity and/or the patient reached hormonal remission following resection.

The most common signs were weight gain, typical Cushing's stigmata, muscle weakness and hypertension. The thorax was the most prevalent tumor location (11/15 patients). Six tumors were classified as typical and 2 as atypical bronchial carcinoids (according to the WHO classification of 2004; Travis et al. 2004), 3 were smallcell lung carcinomas (SCLC), 1 low-grade mediastinal paraganglioma, 1 choriocarcinoma and 2 were classified as carcinoma of unknown primary (CUP) tumor. Tissue was available only from liver metastasis in 2 cases. Overall, metastases were detected in 10 patients ( 3 with SCLC, 1 with the germ cell tumor, 2 with CUP, 2 with atypical and 2 with typical bronchial carcinoid) and were rare in patients with well-differentiated tumors ( 5 bronchial carcinoids and 1 paraganglioma).

Sanger sequencing showed that all 15 cases were wildtype for the USP8 hotspot located in exon 14. USP8 immunoreactivity (1:1000, Sigma) was detected in all

Published by Bioscientifica Ltd 
tumors (Fig. 1). The average semiquantitative $H$-score did not differ for SCLC $(2.4 \pm 0.6)$, bronchial carcinoids $(2.3 \pm 0.7)$, atypical bronchial carcinoids $(2.1 \pm 1.3)$ and others $(2.3 \pm 0.4 ; P=0.961)$. Positive immunoreactivity for ACTH (1:200, Dako) was detected in 9/15 tumors (7 bronchial carcinoids, 1 CUP and the paraganglioma) (Fig. 1). The 3 cases of SCLC, 1 CUP and the choriocarcinoma were negative for ACTH (one-way ANOVA, $P=0.03$ ), as was described for malignant EAS tumors (Coates et al. 1986). Two cases immunonegative for ACTH showed immunoreactivity for $\mathrm{CRH}$ using a rabbit polyclonal antibody (C-13XVII): the choriocarcinoma and 1 SCLC.

EGFR immunostaining (1:200, Cell Signaling Technologies) was observed in 8/15 tumors (3 typical
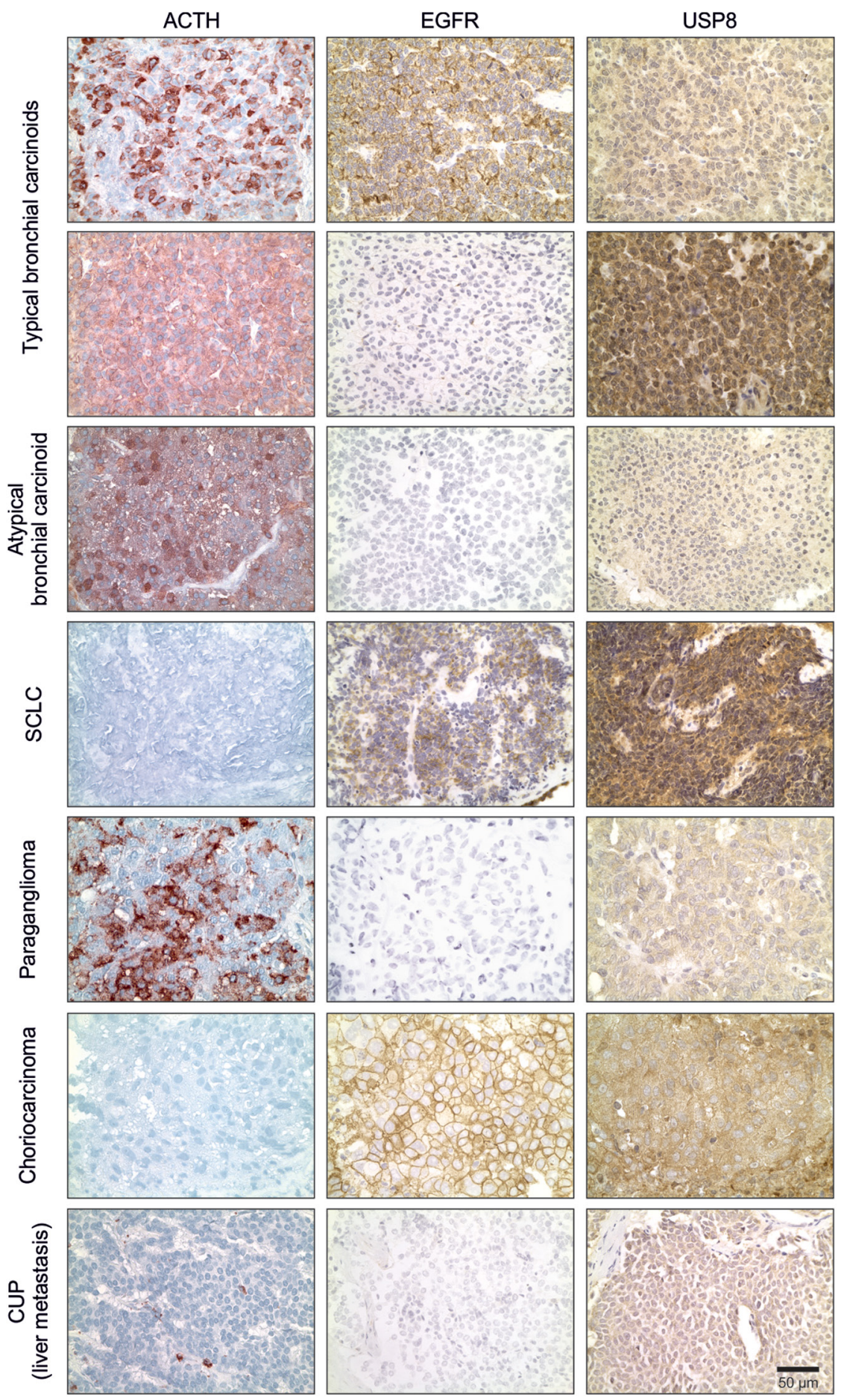
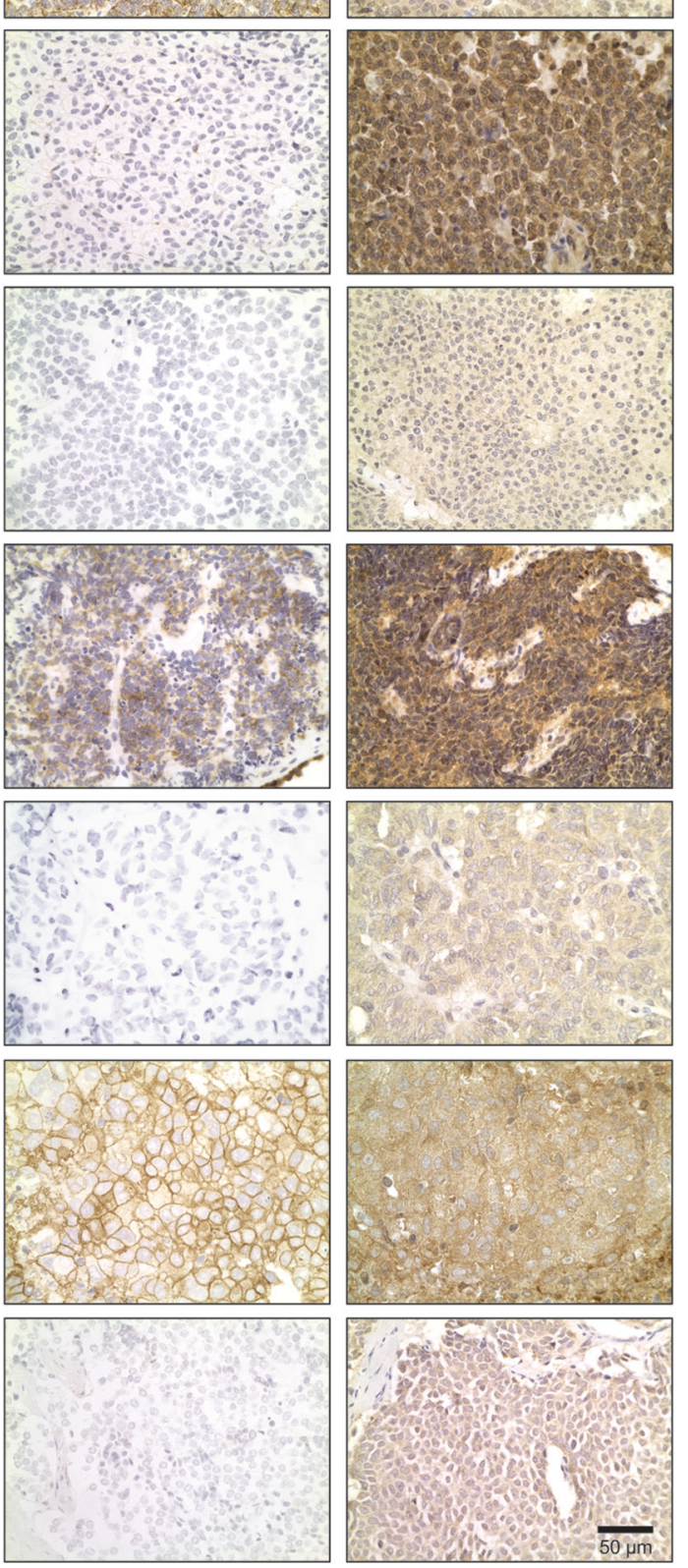
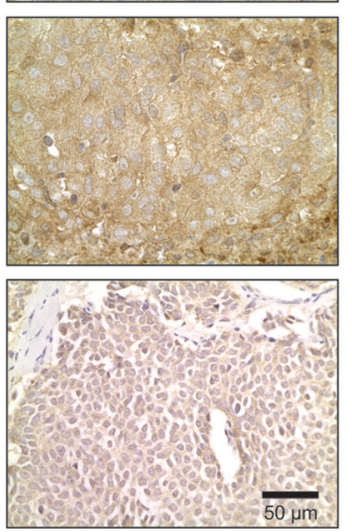

Figure 1

Immunohistochemical stainings of ACTH, EGFR and USP8 in a representative typical bronchial carcinoid, an atypical bronchial carcinoid and a small-cell lung carcinoma. Counterstaining was done with toluidine blue (ACTH) and hematoxylin (EGFR and USP8). 
and 1 atypical bronchial carcinoids, 2 SCLC, 1 CUP and the choriocarcinoma; Fig. 1). Only 3 samples, all typical bronchial carcinoids, were positive for both EGFR and ACTH. Four bronchial carcinoids (1 atypical and 3 typical), 1 SCLC, 1 CUP and the paraganglioma were immunonegative. EGFR expression did not correlate with tumor type ( $H$-scores for SCLC $1.7 \pm 1.5$, typical bronchial carcinoids $1.1 \pm 1.3$, atypical bronchial carcinoids $1.5 \pm 2.1$ and others $1.2 \pm 1.5 ; P=0.951)$. This expression pattern was similar to those reported for pulmonary carcinoid tumors, which express EGFR in no more than 50\% of cases (Rickman et al. 2009).

No correlation was found between USP8 and ACTH $\left(R^{2}=0.064 ; P=0.363 ; 95 \%\right.$ CI $\left.-0.481,0.170\right)$ or EGFR immunoreactivities $\left(R^{2}=0.008 ; P=0.957 ; 95 \%\right.$ CI -0.373 , 0.233) or between EGFR or USP8 immunoreactivities and age at diagnosis $(P=0.599$ and $P=0.991$, respectively), sex $(P=0.469$ and $P=0.167)$, body mass index $(P=0.504$ and $P=0.525)$, basal plasma ACTH $(P=0.896$ and $P=0.773)$, cortisol production $(P=0.683$ and $P=0.975)$, clinical remission $(P=0.359$ and $P=0.858)$, recurrence $(P=0.154$ and $P=0.667)$ and survival $(P=0.321$ and $P=0.323)$.

We examined the impact of USP8 on ectopic ACTH synthesis in vitro in NCI-H727 (well-differentiated bronchial carcinoid) and DMS79 (SCLC) cells. USP8 overexpression or knock-down did not affect endogenous POMC transcription in DMS79 cells (Fig. 2A and B), contrary to pituitary ACTH-secreting AtT-20 cells where USP8 overexpression significantly increased endogenous Pomc transcription and Usp8 knock-down had the opposite effect $(P=0.0290$, Fig. $2 \mathrm{~A}$ and $P=0.0046$, Fig. 2B respectively). No $P O M C$ transcript was detected in the NCI-H727 cells; therefore, to study the potential effect of USP8, we used a reporter vector that has the luciferase gene
A
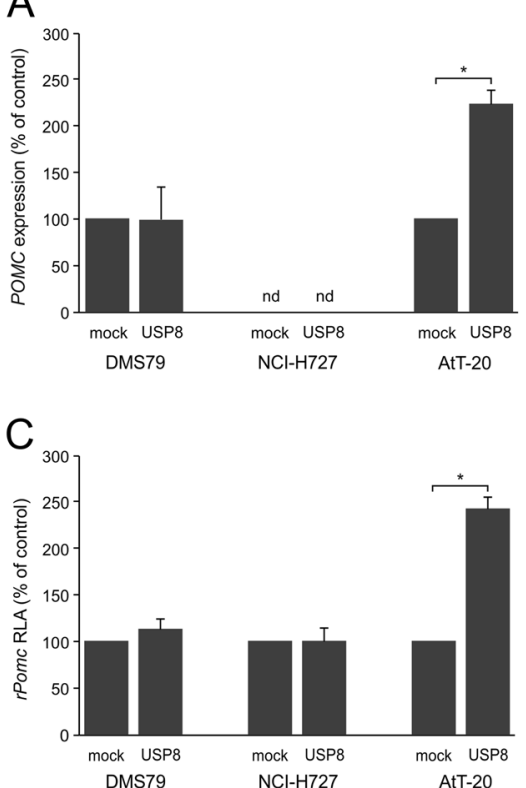

$E$

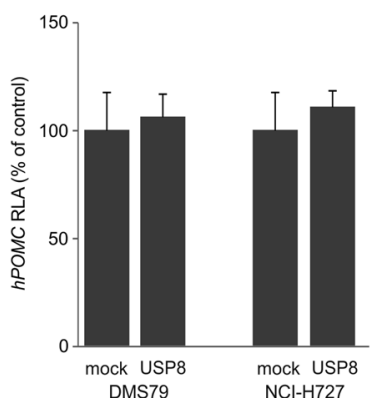

$\mathrm{F}$

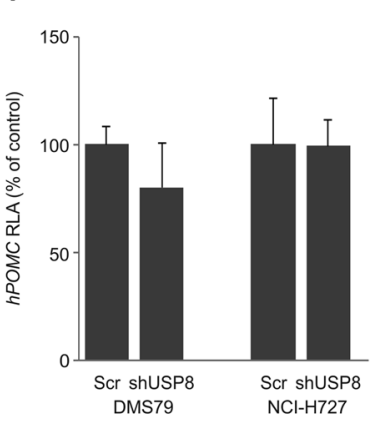

B
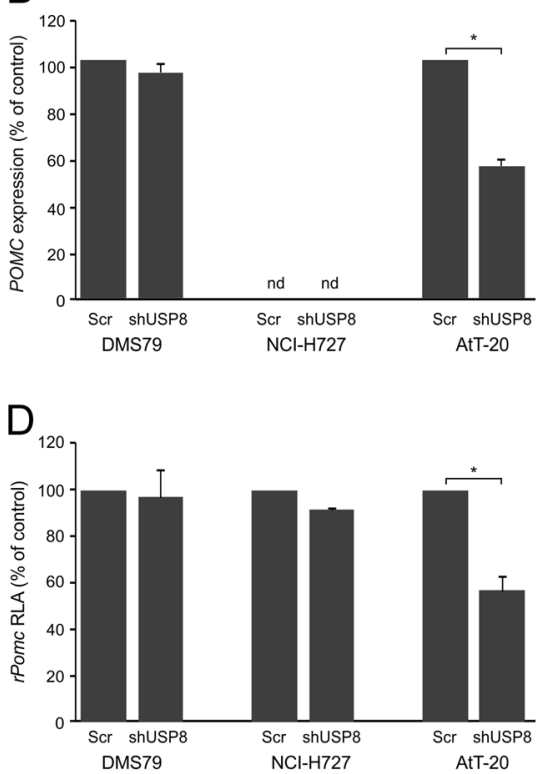

G

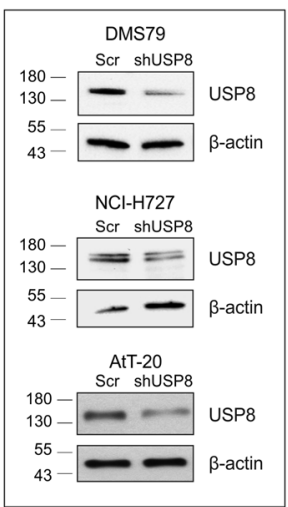

Figure 2

Effect of USP8 on POMC transcription in neuroendocrine DMS79 and $\mathrm{NCl}-\mathrm{H} 727$ cells. (A) Endogenous POMC transcription in cells overexpressing human USP8 as determined by real-time RT-PCR vs pituitary ACTH-secreting AtT-20 cells. The empty pME-Flag vector was used as control (mock). (B) Endogenous POMC transcription after knocking down human (DMS79, NCl-H727) or mouse (AtT-20) USP8 with a specific shRNA for USP8. A scramble shRNA was used as control. Both plasmids also coded for GFP. After transfection cells were left in medium supplemented with $2 \%$ fetal calf serum for four days and then green fluorescent cells were sorted. Both RNA and proteins were extracted for qPCR (B) and Western blot (G). Data are means \pm standard deviation of 3 measurements, calculated as POMC/TFIIB and presented as $\%$ of each control. nd, not-detected. (C, D, E and F) Effect of USP8 overexpression or knock-down on rat Pomc (C and D) or human POMC promoter activity ( $E$ and $F$ ). Data are represented as means \pm standard deviation of 3 measurements (error bars), calculated as luciferase-to- $\beta$ galactosidase ratio and presented as percentage of each control. RLA, relative luciferase activity. Measurements were compared to the control condition using $t$-test. ${ }^{\star} P<0.05$. (G) Knock-down efficacy was monitored by Western blot for USP8. $\beta$ actin was used as control. 
under the control of the rat Pomc promoter (Reincke et al. 2015). USP8 overexpression or inhibition with shRNA did not affect Pomc promoter activity in NCI-H727 or DMS79 cells (Fig. 2C and D). In contrast, in AtT-20 cells, its overexpression triggered and its inhibition reduced rat Pomc promoter activity $(P=0.0036$, Fig. $2 \mathrm{C}$ and $P=0.0105$, Fig. 2D respectively). Species-specific regulation patterns between rodent and human POMC transcription have to be considered when extrapolating results from pituitary corticotroph (murine) to EAS (human) cell line (Araki et al. 2016). Accordingly, we examined the effect of USP8 overexpression and knock-down on a human POMC promoter (Panomics) in the two human neuroendocrine cell lines and observed the same lack of response.

In summary, we show that, contrary to the pituitary ACTH-secreting tumors, the USP8 hotspot sequence on exon 14 is not mutated in tumors causing EAS. Although USP8 is expressed in all EAS tumors examined, our in vitro data indicate that it is not involved in the regulation of ectopic POMC transcription. POMC transcription in neuroendocrine neoplasias has been reported to be independent from the transcription factors Pitx1, Tpit and NeuroD1/Ascl1 that drive pituitary POMC transcription (reviewed in Drouin 2016) (Araki et al. 2016). Thus, the differential response of pituitary and extra-pituitary POMC transcription to USP8 highlights these regulatory differences and showcases USP8 as a pituitary-specific regulator of ACTH synthesis. In conclusion, mutations in USP8 are absent in tumors producing ectopic ACTH and the USP8 expression observed in EAS tumors is insufficient to induce extra-pituitary POMC transcription.

Luis G Perez-Rivas Andrea Oßwald 1 Thomas Knösel ${ }^{2}$

Kristin Lucia1,3 Christian Schaaf ${ }^{2}$ Michael Hristov ${ }^{4}$ Julia Fazel ${ }^{1}$ Thomas Kirchner ${ }^{2}$ Felix Beuschlein ${ }^{1}$ Martin Reincke ${ }^{1}$ Marily Theodoropoulou ${ }^{1,3}$

${ }^{1}$ Medizinische Klinik und Poliklinik IV, Ludwig-MaximiliansUniversität München, Munich, Germany ${ }^{2}$ Institute of Pathology, Ludwig-Maximilians-Universität München, Munich, Germany ${ }^{3}$ Department of Endocrinology, Max Planck Institute of Psychiatry, Munich, Germany
4Institute for Cardiovascular Prevention, LudwigMaximilians-Universität München, Munich, Germany

(Correspondence should be addressed to M Theodoropoulou; email: Marily.Theodoropoulou@med.uni-muenchen.de)

Declaration of interest

The authors declare that there is no conflict of interest that could be perceived as prejudicing the impartiality of the research reported.

\section{Funding}

The work received funding from the European Union's Seventh Framework Programme for research, technological development and demonstration activities under grant agreement no. 608765 and the Ludwig-MaximiliansUniversität München through the K.L. Weigand'schen Stiftung, CurtBohnewands-Fonds and the Georg und Traud Gravenhorst-Stiftung. L G P-R is supported by a grant from the German Research Foundation (Grant RE 752/20-1). The German Cushing's registry is supported by a grant of the Else Kröner-Fresenius Stiftung to M R (2012_A103 and 2015_A228).

\section{Acknowledgements}

The authors thank Brigitte Mauracher (LMU München), Johanna Stalla and Jose Luis Monteserin-Garcia (MPI Psychiatry) for the excellent technical assistance. They apologize to all authors whose important contributions on the Cushing's syndrome field could not be cited due to the imposed restrictions in references number.

\section{References}

Alexandraki KI \& Grossman AB 2010 The ectopic ACTH syndrome. Reviews in Endocrine and Metabolic Disorders 11 117-126. (doi:10.1007/s11154-010-9139-z)

Araki T, Liu N-A, Tone Y, Cuevas-Ramos D, Heltsley R, Tone M \& Melmed S 2016 E2F1-mediated human POMC expression in ectopic Cushing's syndrome. Endocrine-Related Cancer 23 857-870. (doi:10.1530/ERC-16-0206)

Coates PJ, Doniach I, Howlett TA, Rees LH \& Besser GM 1986 Immunocytochemical study of 18 tumours causing ectopic Cushing's syndrome. Journal of Clinical Pathology 39 955-960. (doi:10.1136/ jcp.39.9.955)

Drouin J 201660 YEARS OF POMC: transcriptional and epigenetic regulation of POMC gene expression. Journal of Molecular Endocrinology 56 T99-T112. (doi:10.1530/JME-15-0289)

Ma Z-Y, Song Z-J, Chen J-H, Wang Y-F, Li S-Q, Zhou L-F, Mao Y, Li Y-M, Hu R-G, Zhang Z-Y, et al. 2015 Recurrent gain-of-function USP8 mutations in Cushing's disease. Cell Research 25 306-317. (doi:10.1038/cr.2015.20)

Nieman LK, Biller BMK, Findling JW, Newell-Price J, Savage MO, Stewart PM \& Montori VM 2008 The diagnosis of Cushing's syndrome: an Endocrine Society Clinical Practice Guideline. Journal of Clinical Endocrinology and Metabolism 93 1526-1540. (doi:10.1210/jc.2008-0125)

Perez-Rivas LG, Theodoropoulou M, Ferraù F, Nusser C, Kawaguchi K, Stratakis CA, Rueda Faucz F, Wildemberg LE, Assié G, Beschorner $\mathrm{R}$, et al. 2015 The gene of the ubiquitin-specific protease 8 is frequently mutated in adenomas causing Cushing's disease. Journal of Clinical Endocrinology and Metabolism 100 E997-E1004. (doi:10.1210/jc.2015-1453) 
Reincke M, Sbiera S, Hayakawa A, Theodoropoulou M, Osswald A, Beuschlein F, Meitinger T, Mizuno-Yamasaki E, Kawaguchi K, Saeki Y, et al. 2015 Mutations in the deubiquitinase gene USP8 cause Cushing's disease. Nature Genetics 47 31-38. (doi:10.1038/ ng.3166)

Rickman OB, Vohra PK, Sanyal B, Vrana JA, Aubry M-CC, Wigle DA \& Thomas CF 2009 Analysis of ErbB receptors in pulmonary carcinoid tumors. Clinical Cancer Research 15 3315-3324. (doi:10.1158/10780432.CCR-08-2549)
Terzolo M, Reimondo G, Alì A, Bovio S, Daffara F, Paccotti P \& Angeli A 2001 Ectopic ACTH syndrome: molecular bases and clinical heterogeneity. Annals of Oncology 12 (Supplement 2) S83-S87. (doi:10.1093/annonc/12.suppl_2.s83)

Travis WD, Brambilla E, Müller-Hermelink HK \& Harris CC 2004 Pathology \& genetics: tumours of the lung, pleura, thymus and heart. In World Health Organization Classification of Tumours. Lyon, France: IARC Press. (available at: http://www.iarc.fr/en/ publications/pdfs-online/pat-gen/bb10/)

Received in final form 24 June 2017

Accepted 13 July 2017

Accepted Preprint published online 14 July 2017
Published by Bioscientifica Ltd. 